\title{
Editorial
}

\section{Indicators for monitoring cataract surgery outcomes; evolution and importance}

\author{
Khandekar $\mathrm{R}^{1}$, May $\mathrm{W}^{1,2}$, Alasbali $\mathrm{T}^{3}$ \\ ${ }^{1}$ King Khaled Eye Specialist Hospital, Riyadh, Saudi Arabia \\ ${ }^{2}$ Wilmer Eye Institute, Maryland, USA \\ ${ }^{3}$ Imam Mohammed bin Saud Islamic University College of Medicine, Riyadh, Saudi Arabia
}

Cataract is one of the leading causes of blindness globally (Pascolini \& Mariotti, 2012). Cataract surgery restores vision and is a cost-effective health intervention ranked second to the vaccination. In the 'VISION 2020 -The Right to Sight' initiative, cataract is given the highest priority so that member countries of the World Health Organization can eliminate avoidable blindness by the year 2020 (World Health Organization, 2007). From a public health perspective, the quantity and quality of cataract surgery is important. Hence, indicators to monitor cataract surgeries are both quantitative and qualitative. These indicators have changed along with the evolution of cataract services.

In the era of intracapsular cataract extraction using the Von Graefe knife and without applying any sutures, the follow-up teams at cataract surgery camps used to test vision by placing ready-made spectacles of $+10 \mathrm{D}$ power. If the patient could see a tree through an open window or recognise acquaintances or relatives standing nearby, cataract surgery was considered successful. If some cases of postoperative endophthalmitis developed following a cataract surgery camp, camp personnel were not notified and other health professionals like optometrists and nurse, used to manage these cases, which might already have developed into advanced stages. Postoperatively, patients were instructed not to move their heads for a few days. Eventually after surgery, patients had to wear thick-lens spectacles for restoring distance and near vision.

The advent of extracapsular cataract extraction and suturing improved the prognosis of cataract surgery. Cataract surgery was monitored based on the percentage proportion of cases with best-corrected vision between $6 / 6$ to $6 / 18$ and the rate of intraoperative complications (Pararajasegaram R, 2002). Patients were still advised to restricted mobility for some time postoperatively. The availability of contact lenses in urban populations or implantation of anterior chamber intraocular lens by some surgeons often at distant locales phased out thick aphakic glasses. However, patients still required reading glasses postoperatively. Over time, the indicators for successful visual outcome included unaided and best-corrected distance visual acuity, percentage proportion of IOL surgeries and rates of intraoperative complications.

\footnotetext{
Address for Correspondence

Dr Rajiv Khandekar, Head of ophthalmic epidemiology and

low vision services, King Khaled Eye Specialist Hospital, POB:

7191, Riyadh, 11462, Saudi Arabia.

Tel: 966114821234 Ext: 1131, Fax: 966114829311

Email: Rajiv.khandekar@gmail.com
} 
Extracapsular cataract extraction with posterior chamber lens implantation with or without phacoemulsification between 1979 and 1991 yielded good results. However, complication rates were very high and posterior capsule opacification caused decreased visual acuity a few years after surgery (Powe et al., 1994). There was greater surgicallyinduced astigmatism with small incision extracapsular cataract extraction and lens implantation compared to phacoemulsification and cataract surgery(Riaz et al., 2006).

The recommendation is to use quantitative indicators such as cataract surgery rates (CSR) and CSR among the $>50$ population per million population yearly to reach the goals of eliminating cataract-related blindness by the year 2020 (Murthy et al, 2008). However, presenting vision and lens status of the fellow eye could further influence the target CSR.

Limburg etal proposed a method to monitor cataract surgery outcomes using preoperative and postoperative distance visual acuity (Limburg, et al, 1999). Subsequently, they introduced and offered free software to cataract surgeons in developing countries to encourage them to incorporate quality assurance procedures in the management of cataract-related blindness (Limburg et al, 2005). This auditing system also helped identify the causes of poor cataract surgery outcomes such as, ocular comorbidities, uncorrected refractive error, intraoperative and immediate postoperative complications and late postoperative complications. Institutions performing large-volume cataract surgery are using audit systems to monitor cataract surgeries and are proactively improving their performance (Khandekar, et al, 2010), (Gogate, et al 2011).

The effect of cataract on different visual functions is not new to eye care providers (Elliott, 1993). Low contrast charts are often used to identify visual disability during early stage cataract development. Multifocal intraocular lens originally caused impaired visual function postoperatively, which resulted in closer monitoring of contrast sensitivity and glare (de Vries \& Nuijts, 2013). Currently, assessment tools such as the visual function questionnaire (VF-15) are available to monitor cataract surgery outcomes (Garcia-Gutierrez et al., 2014). However, their use is limited for research purposes but can form an integral component of an audit system. New methods to assess visual function by automated instruments to create real- life scenarios could be better monitoring tools (Gomez, 2014).

Over time, multifocal intraocular lenses and surgical techniques were refined resulting in good uncorrected near vision following cataract surgery, which was key to greater patient satisfaction (Lundström \& Stenevi, 2013). Surgeons using mono-focal lens may try to leave the non-dominant eye myopic up to a level of 2D thus creating 'Mono vision' with one eye functioning for near vision. In such situations, the status of near vision as a monitoring indicator should be used with caution.

The cost of cataract surgery is a barrier to increasing the volume of cataract surgery globally. Therefore, the cost of the intervention should be monitored to ensure it is not limiting uptake or prohibitive to patients seeking care. Over the last decade, outpatient cataract surgery has resulted in decreasing the cost of surgery without compromising the quality of outcomes (Fedorowicz, et al, 2011). 
The ultimate goal of ocular management is to improve the patient's vision-related quality of life (VQL) and health-related quality of life (HQL). Patients who underwent surgery for senile cataract had an overall improvement in VQL but mobility-related improvement in VQL is remarkable (Lee \& Wilson, 2000). Although the risk of falls among the elderly decreases after modern cataract surgery (Sach et al., 2007), Lee et al noted limited changes in their HQL following cataract surgeries.

Both in industrialised and developing countries, eye care providers in private sectors contribute to reducing visual disabilities due to cataract. However evidence regarding regular cataract surgery audits and type of monitoring tools is limited. As a result, generating reliable data on cataract surgery outcomes (qualitative and quantitative) at national and international levels is often a challenge.

The Rapid Assessment method for cataract blindness was first reported in 1989 (Venkataswamy et al., 1989) and was subsequently included as an integral component of the Rapid Assessment of Avoidable Blindness (Marmamula, et al, 2012). In such surveys, information on cataract surgery outcomes of a region on a sample basis is available. These surveys demonstrate the changing trends of cataract surgeries and their benefits in reducing visual disabilities and improving quality of life.

Many ophthalmologists consider the number of patients coming to the same surgeon to undergo cataract surgery in the fellow eye and referral of their relatives for cataract surgery as a proxy indicator for satisfaction and quality of services rendered. To the best of our knowledge, these indicators to monitor cataract services are not mentioned in the literature.

Over the last three decades, there has been substantial evolution in cataract surgeries as well as in the monitoring of the outcomes. The most recent advancement is femtosecond laser assisted cataract surgeries (FLACS) (Alio, et al, 2014). It is a challenging task to keep pace with the continual developments and set outcome benchmarks that are practical and acceptable to all stakeholders (Lindfield, et al, 2012). The audit initiatives will help improve the performance of the surgical team. Additionally, the initiatives will improve the eyesight of senior citizens whose life expectancy is gradually increasing and who can therefore continue to contribute effectively to society.

\section{References}

Alio JA, Abdu AA, Puente AA, et al (2014). Femtosecond Laser Cataract Surgery: Updates on Technologies and Outcomes. Journal of Refractive Surgery 30(6);420-427.

De Vries, N. E., \& Nuijts, R. M. M. A. (2013). Multifocal intraocular lenses in cataract surgery: literature review of benefits and side effects. Journal of Cataract and Refractive Surgery 39(2), 268$z 78$.

Elliott, D. B. (1993). Evaluating visual function in cataract. Optometry and Vision Science: Official Publication of the American Academy of Optometry 70(11), 896-902.

Fedorowicz, Z., Lawrence, D., Gutierrez, P., \& van Zuuren, E. J. (2011). Day care versus in-patient surgery for age-related cataract. The Cochrane Database of Systematic Reviews (7), CD004242. 
Garcia-Gutierrez, S., Quintana, J. M., Aguire, U., Barrio, I., Hayas, C. L., Gonzalez, N., \& IRYSSCataract Group. (2014). Impact of clinical and patient-reported outcomes on patient satisfaction with cataract extraction. Health Expectations: An International Journal of Public Participation in Health Care and Health Policy 17(6), 765-775.

Gogate, P., Vakil, V., Khandekar, R., Deshpande, M., \& Limburg, H. (2011). Monitoring and modernization to improve visual outcomes of cataract surgery in a community eye care center in western India. Journal of Cataract and Refractive Surgery 37(2), 328-334.

Gomez, M. L. (2014). Measuring the quality of vision after cataract surgery. Current Opinion in Ophthalmology 25(1), 3-11.

Khandekar, R. B., Jain, B. K., Sudhan, A. K., \& Pandey, K. P. (2010). Visual acuity at 6 weeks after small incision cataract surgery and role of audit in predicting visual acuity. European Journal of Ophthalmology 20(2), 345-352.

Lee, B. L., \& Wilson, M. R. (2000). Health-related quality of life in patients with cataract and glaucoma. Journal of Glaucoma 9(1), 87-94.

Limburg, H., Foster, A., Gilbert, C., Johnson, G. J., \& Kyndt, M. (2005). Routine monitoring of visual outcome of cataract surgery. Part 1: Development of an instrument. The British Journal of Ophthalmology 89(1), 45-49.

Limburg, H., Foster, A., Vaidyanathan, K., \& Murthy, G. V. (1999). Monitoring visual outcome of cataract surgery in India. Bulletin of the World Health Organization 77(6), 455-460.

Lindfield, R., Vishwanath, K., Ngounou, F., \& Khanna, R. C. (2012). The challenges in improving outcome of cataract surgery in low and middle income countries. Indian Journal of Ophthalmology 60(5), 464-469.

Lundström, M., \& Stenevi, U. (2013). Analyzing patient-reported outcomes to improve cataract care. Optometry and Vision Science 90(8), 754-759.

Marmamula, S., Keeffe, J. E., \& Rao, G. N. (2012). Rapid assessment methods in eye care: an overview. Indian Journal of Ophthalmology 60(5), 416-422.

Murthy, G., Gupta, S. K., John, N., \& Vashist, P. (2008). Current status of cataract blindness and Vision 2020: the right to sight initiative in India. Indian Journal of Ophthalmology 56(6) 489-494.

Pararajasegaram R. (2002) Importance of monitoring cataract surgical outcomes. Community Eye Health 15(44):49-50.

Pascolini, D., \& Mariotti, S. P. (2012). Global estimates of visual impairment: 2010. British Journal of Ophthalmology 96(5), 614-618.

Powe, N. R., Schein, O. D., Gieser, S. C., Tielsch, J. M., Luthra, R., Javitt, J., \& Steinberg, E. P. (1994). Synthesis of the literature on visual acuity and complications following cataract extraction with intraocular lens implantation. Cataract Patient Outcome Research Team. Archives of Ophthalmology 112(2), 239-z52.

Riaz, Y., Mehta, J. S., Wormald, R., Evans, J. R., Foster, A., Ravilla, T., \& Snellingen, T. (2006). Surgical interventions for age-related cataract. The Cochrane Database of Systematic Reviews (4), CD001323. 
Sach, T. H., Foss, A. J. E., Gregson, R. M., Zaman, A., Osborn, F., Masud, T., \& Harwood, R. H. (2007). Falls and health status in elderly women following first eye cataract surgery: an economic evaluation conducted alongside a randomised controlled trial. The British Journal of Ophthalmology 91(12), 1675-1679.

Venkataswamy, G., Lepkowski, J. M., Ravilla, T., Brilliant, G. E., Shanmugham, C. A., Vaidyanathan, K., \& Tilden, R. L. (1989). Rapid epidemiologic assessment of cataract blindness. The Aravind Rapid Epidemiologic Assessment Staff. International Journal of Epidemiology 18(4 Suppl 2), S60-67. 